\title{
Insights into the expectations of mobility students: the impact of Erasmus in their future professional careers
}

\author{
Simões, Dora ${ }^{\text {ab }}$; Pinheiro, Margarida ${ }^{\text {ac }}$; Santos, Claudia Amaral ${ }^{\text {ad }}$; Filipe, Sandra ${ }^{\text {ae }}$; \\ Barbosa, Belém $^{\text {ae }}$; and Dias, Gonçalo Paiva ${ }^{\text {fe }}$ \\ ${ }^{\text {a }}$ Aveiro Institute of Accounting and Administration, University of Aveiro (ISCA-UA), \\ ${ }^{\mathrm{b}}$ CIC.DIGITAL/Digimedia - Digital Media and Interaction, ${ }^{\mathrm{c}}$ CIDTFF Research Centre \\ Didactics and Technology in Education of Trainers, ${ }^{\mathrm{d}}$ CLLC Languages, Literatures and \\ Cultures Research Centre, ${ }^{e}$ GOVCOPP Research Unit on Governance, Competitiveness and \\ Public Policies, ${ }^{\mathrm{f}}$ Águeda School of Technology and Management, University of Aveiro \\ (ESTGA-UA).
}

\begin{abstract}
At the celebration of its 30th anniversary, Erasmus is recognised as the most successful exchange program ever implemented. The prospects of attaining a common European consciousness challenged the program's ability to blend together knowledge, attitudes and skills in a winning combination. It is no longer sufficient to communicate and integrate: mobility should actively foster skills to support students's professional career at national and international levels. Although literature on mobility is vast and interesting, studies on the impact of the mobility experience in the students' future employability profile rarely provide first-hand data on their expectations in this regard. This exploratory research comprises a qualitative focus group approach with Erasmus students during their exchange period in a Portuguese university and collected some insightful data on how students consider their mobility in terms of new learning outcomes, the professional value of the experience and the development of new skills. Results indicate that students seem to be quite aware of the positive implications of mobility in their professional careers and of the set of skills developed during that period. Overall, this article contributes to demonstrating the importance of assessing skills development during Erasmus mobility experiences. Managerial implications and suggestions for future research are provided.
\end{abstract}

Keywords: Eramus mobility program; employability skills; career impact of Erasmus; mobility students; Erasmus students'skills. 


\section{Introduction}

More than 3 million individuals have already benefited from the Erasmus mobility program and for 2014-2020 alone the initiative is expected to contemplate another 5 million citizens. These numbers justify, by themselves, the extended literature around this mobility phenomenon and the recommendations for the need of evaluating its qualitative effects (Huják, 2015), that is to say the need of balancing the paybacks and value created with such programs (Bracht et al., 2006; Engel, 2010).

An important aspect to think through is the relevance of the mobility to the future professional careers of these students. In fact, the goals of internationalization include both blurring national frontiers and preparing students for professional paths in a globalized world, making international careers becoming more and more desirable and a natural consequence (IEREST, 2016). As several authors (e.g., Huják, 2015; Paige et al., 2009) emphasize, the positive impact of the host universities' online communication in a future global career and employability expectations seems to indicate that the international skills acquired or developed during student mobility are an essential outcome.

This research intends to explore students' expectations on the impact the mobility experience may have in their professional careers, together with the set of skills acquired or developed during that period. A qualitative exploratory approach was adopted comprising focus groups composed of Erasmus students that spent at least one semester at the University of Aveiro, Portugal.

\section{Literature review}

The European Commission's primary objective with the Erasmus initiative was to encourage an inclusive approach that would bind together cultural enlightenment, interpersonal experiences, linguistic challenges, academic enrichment and professional opportunities. At the heart of the program was the institutional will and commitment to improve Europe's competitiveness in a knowledge and digital society through education and training. If up to recent years integration and European identity issues were considered the leitmotiv that set in motion hundreds of thousands of students, there seems to be a new trend emphasizing the need to redirect the focus to employability skills. It is a fact that the vast majority of students choose to embark on a mobility experience in their first cycle of studies, probably not pondering too much on whether their adventure will be converted in a real asset when applying for a job or when actually performing the job. In turn, industry practicioners in general have been paying special attention to the assessment of the intangible aspects of 'mobile' applicants and tend to value an holistic approach of graduate's profile, rating their employability potential in line with a recommended set of interpersonal, 
management and academic skills including, among others, communication and language proficiency, inititiave, motivation, planning and organizing, time management, problemsolving, self-awareness, teamwork spirit, research and innovation, decision-making, problem solving and resilience capacities.

Extant literature provides rich contributions on the motivations to student mobility, including speaking a new language, improving communication abilities, and enrich personal development through independence and confidence (Van Maele, et al., 2016). Mobility is also referred as an opportunity for students to to learn something new about themselves and enhance their cultural horizon. Still, doubt remains on the impact of mobility experiences on professional and employability skills (Coleman, 2015; Paige et al., 2009). While some studies (e.g., Bracht, et al., 2006; Engel, 2010) report positive impacts of students' intercultural learning in their professional development, others argue that exposure to a new environment is not sufficient to have an impact on their careers (Alfranseder, et al., 2011). Moreover, several studies (e.g., Lesjak, et al., 2015; Van Mol \& Ekamper, 2016) concluded that students are mainly motivated by experiental goals (personal growth) and not by academic or professional goals (professional growth). Nevertheless, Lesjak and colleagues (2015) showed that students tend to choose developing countries due to the increased probability of encountering new educational systems and employability opportunities.

Regarding the expectations that students realize in employment opportunities after participating in an Erasmus program, González and coleagues (González, et al. 2011) argue that there are some differences across regions. These authors determine that both European and American students are motivated by better job opportunities. However, European students hoped that this experience whould increase their chances of employment outside their home country while American students hope for better employment opportunities within their home country. Several other studies (e.g., Findlay, et al.; Lesjak, et al., 2015) point out that the knowledge of foreign languages, especially the most common ones, is perceived by students has having a strong impact on a future professional career. So, this appears to be the main reason why students go abroad, and not only to complement their core studies (Lesjak, et al., 2015). 


\section{Methodology}

Taking into account the contributions collected in the literature review and the proposed research objectives, a qualitative exploratory approach was adopted with the purpose of assessing students' perceptions and expectations on the impacts of mobility on their future professional careers. The phenomenological interview is an inductive methodology guided by a central question that attemps to identify a specific phemenon by providing the actors total freedom of expression and reasoning.

A convenience sample was defined comprising a total of 15 students on mobility in the University of Aveiro in the Fall/Winter semester 2016. Focus group interviews were organized into three topics: (i) What do Erasmus students learn during the mobility experience that otherwise could not have learned?; (ii) How valuable is the Erasmus experience expected to be for their future careers?; and (iii) What new skills do Erasmus students develop? The focus groups where held in mid-December so participants had been in Aveiro for three months and about to conclude their exchange semester.

Table 1: Sample characterization

\begin{tabular}{cccccc}
\hline $\begin{array}{c}\text { Focus } \\
\text { group }\end{array}$ & Gender & Continent & Country & Age & $\begin{array}{c}\text { First Mobility } \\
\text { Experience? }\end{array}$ \\
\hline 1 & female & Europe & Czech Republic & 22 & yes \\
1 & female & Europe & Czech Republic & 22 & yes \\
1 & female & Europe & Italy & 23 & yes \\
1 & female & Europe & Latvia & 22 & yes \\
1 & female & Europe & Poland & 21 & yes \\
1 & female & Europe & Poland & 21 & yes \\
2 & female & America & -- & 21 & no \\
2 & male & America & -- & 22 & no \\
2 & female & Europe & Spain & 22 & yes \\
2 & male & Europe & Spain & 22 & no \\
3 & male & Asia & -- & 36 & no \\
3 & female & Europe & Italy & 23 & yes \\
3 & male & Europe & Italy & 26 & no \\
3 & male & Europe & Poland & 25 & yes \\
3 & male & Europe & Romania & 24 & no \\
\hline
\end{tabular}


Although the study used a convenience sampling method, groups (see Table 1) were organized in order to meet a balanced homogeneity and heterogeneity of participants within groups. Focus group 1 (FG1) comprised only females on their first mobility experience, focus group 2 (FG2) had only Spanish language natives, and focus group 3 (FG3) was composed of the oldest participants in this study. The majority of participants belonged to the study field of humanities and social sciences - management, economics, accounting, finance, marketing, communication. All the interviews where audio recorded with the agreement of all participants. Content analysis' techniques for contextualized interpretations were used.

\section{Results}

As seen in the literature review, the increase in students' mobility can be associated with the expected outcomes acquired or developed during the exchange period, regarded as an initial groundwork for a professional career in a globalized world (IEREST, 2016), fostering independence, confidence and broad-mindedness (Van Maele, Vassilicos, \& Borghetti, 2016), while enriching the educacional environment (European Commission, 2015). The scope of developed skills is large, with a clear improvement of intercultural, interpersonal, management, communication and language competences, valued by all as fundamental, and resulting in a better performance and more professional opportunities.

\subsection{Skills developed during the Erasmus mobility}

As Alfranseder, et al. (2011) mention, an Erasmus' experience creates different learning opportunities. First of all, the practice of a language that is not the mother tongue. This aspect was extensively mentioned by the students and seems to be very challenging:" $I$ learned to make myself comprehensible above and beyond the idiom barrier" (FG2) as "the only option you have is to speak English daily and you do so because you want to communicate with others" (FG2), and because of that "I learned not to be embarrassed of speaking in another language"(FG2). The desire to improve language proficiency skills was not reduced to English: "Of course, Portuguese language itself... it's so cool, you got a lot of more perspectives" and "you become less shy, kind of open up"(FG3). For some, this was actually a mandatory aspect of the mobility: "I just wanted a different idiom." (FG2)

In line with Van Maele, et al. (2016), we found that communication and integration played a major part in the mobility expectations of students: "it is very important to be integrated with other Erasmus and with Portuguese people ... in order to assimilate the new culture" (FG2). Participants also shared the idea that their Erasmus' experience thaught them "to leave your comfort zone, learn by yourself ... be far from home and be confortable" (FG2). Moreover, the mobility experience was clearly valued as an opportunity to develop other 
skills: "with the international experience one can develop competences that could not be improved if no mobility took place"(FG2) like "the ability to be independent, to decide... to manage money, time, to make me understandable with others and to understand another culture" (FG2). The responsibility of being on their own was probably the strongest feeling: "you have to think about doing things and do them well." (FG2)

\subsection{Expected impacts on a future professional career}

Although the literature review indicates that the decision process is not grounded in future professional career expectations, this study found evidence in students' perceptions that sustain a sound awareness of the benefits that an international experience could provide and that may indeed constitute a fundamental motivation for mobility. Following Huják (2015) and Paige et al. (2009), the participants in this study agreed that the skills acquired and developed are "almost compulsory competences at international level... for everybody who wants to go further... develop on one's own, be less afraid of challenges that work might bring" (FG2).

Communication skills are a central point for a future professional career. In fact, participants seem to follow the conclusions of Findlay et al. (2006) and Lesjak et al. (2015), when they consider that "learning Portuguese can open doors in my future professional career as, for instance, you can work with Portugal and then the language can open doors" (FG2). More specifically, in what regards the most common languages, students are unanimous about the advantages of practising and improving their English: "speaking English daily it was very hard... in globalisation everyone needs to speak English" (FG2), emphasizing that "in multinational companies we have to be able to talk in English" (FG1). Along with linguistic competences, comes self-confidence: "to speak more languages makes us more competitive, more attractive to a company" (FG2) and better interpersonal skills: "if you work for an international company..you can learn more about the culture... and now i'm able to talk with other people... and talk about myself" (FG1).

The fact that students are integrated in a community with many nationalities also contributes to their intercultural abilities, aligned with Huják (2015) and Paige et al. (2009): "the integration with other Erasmus and Portuguese students too... different people of different cultures gives you news perspectives of the world... how people think, how people do business, how people act in different parts of the world regarding the same thematics" (FG2). The perceptions on the impact of social skills in their professional career is equally mentioned and considered:"...almost mandatory competences in multinationals ... to know how to manage with people from different countries, to communicate with them" (FG2). 
Another strong added value mentioned in the literature that results from an Erasmus' experience is a broad set of competences covering personal and social skills (Van Maele, et al., 2016), such as organization and planning:"I learned to question my time... you just simply have to organize yourself... and you find you have time for everything" (FG2).

Overall, the participants in this study agreed with the idea that the mobility experience prepares them for an international career, emphasizing that "I will consider working abroad after Erasmus ... Now it seems much easier" (FG3), because "I'm not scared of new adventures"(FG1), "[I am] less frightened... [I have] less stereotypes" (FG3). All these messages seem to reflect the image that students are cleary aware of the possible outcomes of mobility and paying attention to what is expectable from them as future employees: "that is very important because we live in a globalized world and more and more globalized and attentive" (FG2). However, students evidenced some doubts regarding the positive assessement of these employability skills by employers: "For an employer, many don't like a person that travels too much or spends few time in one location... if you have an international experience... if you have studied abroad... it depends on the employer..." (FG3), indicating that there are in fact rather strong expectations on the impacts mobility could import to their professional careers, questioning the appraisal of mobile applicants' employability profiles. Still, "some experience is better than none" (FG3) and being an Erasmus turns out to be something irreplaceable: "...as soon as you join the erasmus you feel this thing... Erasmus people or other international students are a kind of similar group, a niche group, people that have a kind of special perspective of life and of Europe ...the idea that the word is open and that you can go anywhere and you can do anything". Thus, this study provided evidence of the perceived impacts on future professional careers in line with what is suggested by IEREST (2016), but emphasizes the complexity of both the relevant skills and their expected impacts, depending on the amplitude of professional opportunities and even the perceptions of the employers themselves.

\section{Conclusion}

Despite its exploratory nature and scope, this research provides rich empirical evidence on the wider sphere of skills perceived to be developed during student mobility. Moreover, these skills are viewed as fundamental for the participants' future professional careers. While extant literature tends to position professional skills development as a second order reason to spend a semester in another university, this study shows that the implications on future careers are not disregarded by Erasmus students, and in some cases the mobility may trigger international plans beyond the academic stage. Overall, students seem to be clearly paying attention to what is expectable from them as future employees, and that may give employers all the reasons to pay special attention to a deeper assessment of the intangible 
aspects of 'mobile's applicants. In order to foster these important implications and outcomes of Erasmus mobility, universities should provide challenging learning experiences to maximize skills development opportunities, while preparing their students in order to take full advantage of mobility abroad. Again, the evaluation of acquired and developed skills is essential for assessing the success of mobility initiatives.

One brief note on limitations of this study, the main being the scope and dimension of the sample. Thus, new data from new samples, namely from students hosted by universities with both similar and distinct characteristics from Aveiro's, are needed for result validation. In addition, we focused on students' views and expectations, and it will be essential to consider also other parties' views, namely employers, as well as appraising the real outcomes of professional careers by studying former mobility students.

\section{Acknowledgements}

This work is financially supported by National Funds through FCT - Fundação para a Ciência e a Tecnologia, I.P., under the project UID/CED/00194/2013.

\section{References}

Alfranseder, E., Fellinger, J., \& Taivere, M. (2011). E-Value-ate your exchange: research report of the ESNSurvey 2010. Brussels: Erasmus Student Network.

Bracht, O., Engel, C., Kerstin Janson, Over, A., Schomburg, H., \& Teichler, U. (2006). The professional value of ERASMUS mobility. Kassel, Germany.

Coleman, J. (2015). Social circles during residence abroad: what students do, and who with. In R. Mitchell, N. Tracy-Ventura, \& K. McManus (Eds.), Social interaction, identity, and language learning during residence abroad (pp. 33-52). EuroSLA Monographs Series.

Engel, C. (2010). The impact of Erasmus mobility on the professional career: empirical results of international studies on temporary student and teaching staff mobility URL. Belgeo, 4.

European Commission (2015). A statistical overview of the Erasmus Program in 2012-13. Luxembourg.

Retrieved

$3 / 1 / 2017$

from http://ec.europa.eu/dgs/education_culture/repository/education/library/publications/er asmus-stat-2012-13_en.pdf

Findlay, A., King, R., Stam, A., \& Ruiz-Gelices, E. (2006). The changing geographies of UK students studing and working abroad. European Urban and Regional Studies, 13(4), 291-318.

González, C. R., Mesanza, R. B., \& Mariel, P. (2011). The determinants of international student mobility flows: An empirical study on the Erasmus programme. Higher Education, 62(4), 413-430. 
Huják, J. (2015). Study Abroad Programs as Tools of Internationalization: Which Factors Influence Hungarian Business Students to Participate? Journal of Teaching in International Business, 26(1), 56-76.

IEREST. (2016). Intercultural education resources for Erasmus students and their teachers. Bologna. Retrieved 7/1/2017 from http://www.ierestproject.eu/node/12.html

Lesjak, M., Juvan, E., Ineson, E. M., Yap, M. H. T., \& Axelsson, E. P. (2015). Erasmus student motivation: Why and where to go? Higher Education, 70(5), 845-865.

Paige, R. M., Fry, G. W., Stallman, E. M., Josić, J., \& Jon, J. (2009). Study abroad for global engagement: the long- term impact of mobility experiences. Intercultural Education, 20(sup1), S29-S44.

Van Maele, J., Vassilicos, B., \& Borghetti, C. (2016). Mobile students' appraisals of keys to a successful stay abroad experience: Hints from the IEREST project. Language and Intercultural Communication, 16(3), 384-401.

Van Mol, C., \& Ekamper, P. (2016). Destination cities of European exchange students. Geografisk Tidsskrift - Danish Journal of Geography , 116(1), 85-91. 